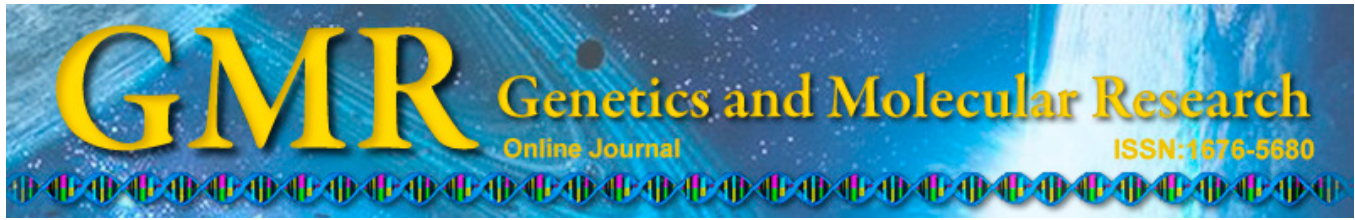

\title{
Molecular cytogenetic identification of a novel 1AL.1RS translocation line with powdery mildew resistance
}

\author{
M. Lu*, L. Wang*, J. Zhang, S. Sun, Y. Li, W. Du, J. Wu, J. Zhao, \\ Q. Yang and X. Chen \\ Shaanxi Key Laboratory of Genetic Engineering for Plant Breeding, \\ College of Agronomy, Northwest A\&F University, Yangling, Shaanxi, China \\ *These authors contributed equally to this study. \\ Corresponding author: X. Chen \\ E-mail: cxh2089@126.com
}

Genet. Mol. Res. 13 (4): 10678-10689 (2014)

Received October 21, 2013

Accepted February 3, 2014

Published December 18, 2014

DOI http://dx.doi.org/10.4238/2014.December.18.10

\begin{abstract}
A wheat germplasm line 13-2-2 with resistance to powdery mildew was isolated; this line was derived from common wheat cv. W770B and rye, Secale cereale L. $(2 \mathrm{n}=2 \mathrm{x}=14, \mathrm{RR})$. The line was characterized based on cytological, genomic in situ hybridization (GISH), sequence-characterized amplified region (SCAR), and simple sequence repeat (SSR) analyses. The mitotic and meiotic investigations showed that the chromosome number and configuration of 13-2-2 were $2 \mathrm{n}=42=21 \mathrm{II}$. GISH using rye genomic DNA as a probe detected a pair of $\mathrm{R}$ genome chromosome arms with strong hybridization signals in 13-2-2. Three 1RS chromosome-specific SCAR markers amplified 1RS specific bands in line 13-2-2. We screened 320 SSR primer pairs on the long or short arms from seven wheat homoeologous groups in the translocation line and parents. However, only three 1AS primers could not be amplified in line 13-2-2, whereas the others were amplified. Thus, these markers suggested that the line 13-2-2 was 1AL.1RS translocation line. Line 13-2-2 was immune to powdery
\end{abstract}


mildew after inoculation with Blumeria graminis f. sp. tritici isolates E05 and E07 during the adult plant stages. In contrast, the maternal parent W770B, Kavkaz with Pm8, and Amigo with $P m 17$ were heavily infected with spores and had reaction response scores of susceptible. Thus, the new wheat-rye 1AL.1RS translocation line with resistance to powdery mildew could be a new and valuable donor source for wheat improvement. The molecular markers developed in this study might also be useful tools for marker-assisted selection.

Key words: 1AL.1RS translocation line; Secale cereale L.; Sequence-characterized amplified region; Simple sequence repeat Genomic in situ hybridization; Triticum aestivum;

\section{INTRODUCTION}

Powdery mildew is a destructive foliar disease caused by Blumeria graminis f. sp. trit$i c i$; it is one of the most devastating diseases that affect wheat production. Instead of applying fungicides and employing specific agronomic practices, the most effective and environmental friendly approach for controlling powdery mildew is breeding resistant cultivars. Over 70 powdery mildew resistance genes/alleles $(\mathrm{Pm})$ have been identified, and 43 loci (Pm1-Pm43) have been mapped (Zhang et al., 2010). These genes have been used extensively in wheat breeding programs; however, many resistance genes are no longer effective because of the increased pathogen virulence and host resistance. Therefore, new resistance genes need to be developed and isolated from Triticum and the wild relatives of wheat.

The introduction of alien chromosomes into wheat from related species is an economical and important method for wheat improvement, particularly disease resistance (Friebe et al., 1996). Rye (Secale cereale L.) has a reservoir of genes that resist biotic and abiotic stresses that have been utilized widely as a valuable source of alien chromosome translocations during wheat breeding (Yediay et al., 2010). Greenbug resistance genes Gb2 and Gb6 (Porter et al., 1991) and powdery mildew resistance gene (Pm8) (Zeller and Fuchs, 1983) have been introduced into wheat via hybridization. The wheat-rye 1BL.1RS translocation lines have been the most widespread alien translocations since the 1970s, and they are used in most wheat-growing areas worldwide (Rabinovich, 1998; Villareal et al., 1998; Lukaszewski, 2000). The 1RS chromosome of T1BL.1RS translocation lines is derived mainly from 'Petkus' rye (Schlegel and Korzun, 1997), whereas the 1RS of 1AL.1RS originated from 'Insave FA' (Secale cereale L.), which was transferred from the octoploid Triticale cultivar 'Gaucho' into hexaploid wheat via X-ray treatment (Sebesta and Wood, 1978). Thus, from a global perspective, numerous wheat varieties and translocation lines have been developed using the rye 1RS chromosome, such as 1AL.1RS, 1BL.1RS, and 1DL.1RS (Friebe et al., 1996; Rabinovich, 1998). They have been important wheat germplasms for wheat improvement and are still used widely by many breeding programs.

Cytogenetic techniques, i.e., chromosome banding and in situ hybridization, have generally been used to screen introgression lines. However, molecular markers such as polymerase chain reaction (PCR)-based markers are more economical and cost-effective for performing marker-assisted selection unlike cytogenetic techniques; in particular, the genomic- and chromosome-specific markers are very efficient and have been widely de- 
veloped and used in wheat breeding (La Rota et al., 2005). Various markers have been developed for detecting rye chromatin and are used extensively, such as restriction fragment length polymorphism (Börner and Korzun, 1998), amplified fragment length polymorphism (Puente et al., 2008), random amplified polymorphic DNA (Ko et al., 2002), sequence-specific amplified polymorphism (Nagy and Lelley, 2003), simple sequence repeat (SSR) (Hackauf and Wehling, 2003), inter-simple sequence repeat (Hess et al., 2000), sequence-characterized amplified region (Stracke et al., 2003), and sequence-tagged sites (Mohler et al., 2001). The specific markers reported for detecting individual rye chromosomes can be used to develop a rapid and reliable marker system for screening wheat lines that contain rye chromatin; this system provides an efficient tool for the selection of desirable lines from large gene pools.

In the present study, we developed a novel wheat-rye derivative line, 13-2-2, which has better agronomic characteristics than the common wheat cv. W770B and has high resistance to powdery mildew. The main objectives of this study are a) to verify the chromosome configuration of 13-2-2 on the basis of cytological analyses and genomic in situ hybridization (GISH) during the mitotic and meiotic metaphases; b) to confirm the genome composition of 13-2-2 by using specific molecular makers; and c) to evaluate the agronomic characteristics and resistance to powdery mildew of 13-2-2.

\section{MATERIAL AND METHODS}

\section{Plant materials}

The hybrid LanR $(2 \mathrm{n}=28, \mathrm{ABDR})$ was obtained in a previous study by crossing common wheat cv. W770B $(2 \mathrm{n}=6 \mathrm{x}=42$, AABBDD $)$ and Mexican Secale cereale L. $(2 \mathrm{n}=2 \mathrm{x}=$ $14, \mathrm{RR}$ ) via embryo rescue; before setting up the cross, the LanR chromosome was doubled by treatment with colchicine. Backcrossing with W770B and further embryo culture led to the development of a new wheat-rye germplasm, Lanxiaohei $(2 n=8 x=56$, AABBDDRR); this was further backcrossed and selfed for six generations. A series of wheat-rye derivative lines were isolated that exhibited stable agronomic performance. One of these lines, 13-2-2 had high resistance to powdery mildew and was isolated from the large population based on cytology and GISH analyses and observations of its resistance reaction in the field. Shaan229 (2n $=6 \mathrm{x}=42$, AABBDD), which was highly susceptible to powdery mildew (Blumeria graminis f. sp. tritici) was used as a susceptible control. Kavkaz with $P m 8$ and Amigo with $P m 17$ were also used as controls to identify the resistance gene of line 13-2-2. Chinese Spring (CS) wheat was used for blocking DNA in the GISH analysis. These plant materials are preserved at the Shaanxi Key Laboratory of Genetic Engineering for Plant Breeding, College of Agronomy, Northwest A\&F University, Shaanxi, China.

\section{DNA extraction and rye genome-specific SCAR markers analysis}

The total genomic DNA of wheat-rye derivative line 13-2-2 and its parents, common wheat $\mathrm{cv}$. W770B and rye, were extracted from fresh leaves using the modified cetyltrimethylammonium bromide (CTAB) method (Cota-Sánchez et al., 2006). To improve the screening efficiency and identify rye chromatin in 13-2-2, we used five rye genome-specific molecular markers, i.e., AF1/AF4 (Francis et al., 1995), D15 (Liu et al., 2007), F3/R3 (Katto et al., 2004), 
$O 5$ (Jia et al., 2012), and P13LF/R (Jia and Yang, 2010) (Table 1). The PCR mixture contents and the amplification procedure were as per published procedures. The products were separated on 1\% agarose gels in 1X TAE buffer, stained with ethidium bromide (EB), and visualized using an automatic gel imaging analysis system.

\begin{tabular}{|c|c|c|}
\hline Marker & Sequence $\left(5^{\prime}-3^{\prime}\right)$ & References \\
\hline$A F 1 / A F 4$ & $\begin{array}{l}\text { F: GGAGACATCATGAAACATTTG } \\
\text { : CTGTTGTTGGGAGAAG }\end{array}$ & (Francis et al., 1995) \\
\hline D15 & $\begin{array}{l}\text { F: CCGGCGTGTCGACACCCTGAT } \\
\text { R: CATCCGTGCTCCGTGTGCATC }\end{array}$ & (Liu et al., 2007) \\
\hline$P 13 L F / R$ & $\begin{array}{l}\text { F: TCCTGTCTAACCACCCTACC } \\
\text { R: TCACTTCCCGAATCCCTTT }\end{array}$ & (Jia et al., 2010) \\
\hline$I B-267$ & $\begin{array}{l}\text { F: GCAAGTAAGCAGCTTGATTTAGC } \\
\text { R: AATGGATGTCCCGGTGAGTGG }\end{array}$ & (Yu et al., 2011) \\
\hline 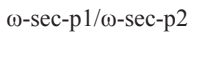 & $\begin{array}{l}\text { F: ACCTTCCTCATCTTTGTCCT } \\
\text { R: CCGATGCCTATACCACTACT }\end{array}$ & (Yu et al., 2011) \\
\hline 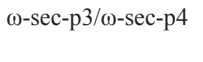 & $\begin{array}{l}\text { F: CCTTCCTCATCTTTGTCCTC } \\
\text { R: GCTCTGGTCTCTGGGGTTGT }\end{array}$ & (Yu et al., 2011) \\
\hline$O 5 F / R$ & $\begin{array}{l}\text { F: CCCAGTCACTACAACGAGAGT } \\
\text { R: GCTACAAGAGCTTCGTGCAG }\end{array}$ & (Jia and Yang, 2010) \\
\hline$F 3 / R 3$ & $\begin{array}{l}\text { F: GATCGCCTCTTTTGCCAAGA } \\
\text { R: TCACTGATCACAAGAGCTTG }\end{array}$ & (Katto et al., 2004) \\
\hline Xgwm163 & $\begin{array}{l}\text { F: CTACCTGCTGTTCCCATTTGG } \\
\text { R: GTGTGTAGAAGATGTTGTCCTGG }\end{array}$ & (Röder et al., 1998) \\
\hline$X w m c 24^{a}$ & $\begin{array}{l}\text { F: GTGAGCAATTTTGATTATACTG } \\
\text { R: TACCCTGATGCTGTAATATGTG }\end{array}$ & - \\
\hline Xgpw $2277^{a}$ & $\begin{array}{l}\text { F: TCAGAAGAGCGATGAGATAGAAA } \\
\text { R: GCCATTTTTAGGGCTCAGTG }\end{array}$ & - \\
\hline
\end{tabular}

aSSR primers were obtained from the database http://wheat.pw.usda.gov. (-) Indicates that no data were recorded.

\section{Cytogenetic analysis}

Seeds were germinated at $23^{\circ} \mathrm{C}$ in the dark on a double layer of a filter paper on a Petri dish. After the roots reached $1-2 \mathrm{~cm}$ in length, the root tips were cut and placed in a tube with ice-cold water for at least $24 \mathrm{~h}$. Next, the water was removed from the root tips, and they were fixed with Carnoy's solution [95\% ethanol:acetic acid, 3:1 (v/v)]. Young spikes were collected at the booting stage and fixed in absolute ethanol-chloroform-glacial acetic acid (6:3:1, v/v). For the cytological observations and GISH analyses of mitotic and meiotic chromosomes, specimens were squashed on a slide in a drop of acetocarmine with $45 \%$ acetic acid. The slides for GISH analyses were prepared by removing the cover slips after freezing in liquid nitrogen, followed by air drying and storage at $-20^{\circ} \mathrm{C}$. GISH was performed according to a previously described procedure (Wu et al., 2006). The rye DNA probe was labeled with digoxigenin (digoxigenin-11-dUTP, DIG; Roche, Germany) using the nick translation method. Fluorescent signals were captured using a cooled CCD camera (Photometrics SenSys) using a fluorescence microscope (Olympus BX60).

\section{RS-specific SCAR marker analysis}

Three rye 1RS-specific SCAR markers located on the 1RS chromosome arm, i.e., IB267 (Yu et al., 2011), $\omega$-sec-p1/ $\omega$-sec-p2 (Yu et al., 2011), and $\omega$-sec-p3/ $\omega$-sec-p4 (Yu et al., 
2011) (Table 1), were used to detect 1RS chromatin in the wheat-rye derivative line 13-2-2. The PCR mixture contents and amplification procedure were as described previously.

\section{SSR analysis}

SSR primer pairs of wheat, i.e., Xgwm2-674 (Röder et al., 1998), Xwmc, Xcfa, Xcfd, $X b a r c$, and Xgpw (from http://wheat.pw.usda.gov), which were distributed evenly on the long and short arms of seven wheat homoeologous groups, were used to further determine the chromosome arms of wheat that were substituted. The PCR sample mixture $(20 \mu \mathrm{L})$ consisted of $2 \mu \mathrm{L}$ 10X PCR buffer, $2 \mu \mathrm{L} 2.5 \mu \mathrm{M}$ primer, $2 \mu \mathrm{L} 40-60 \mu \mathrm{g} / \mu \mathrm{L}$ DNA template, $1.6 \mu \mathrm{L} 2.5 \mu \mathrm{M}$ dNTPs, $1.6 \mu \mathrm{L} 2.5 \mathrm{mM} \mathrm{MgCl}_{2}, 0.1 \mu \mathrm{L} 5 \mathrm{U} / \mu \mathrm{L}$ Taq polymerase, and 10.7 $\mu \mathrm{L} \mathrm{ddH}_{2} \mathrm{O}$. The cycling parameters were as follows: denaturation at $94^{\circ} \mathrm{C}$ for $3 \mathrm{~min}$, followed by 35 cycles at $94^{\circ} \mathrm{C}$ for $1 \mathrm{~min}$, annealing at the specific temperature required by the primers for $50 \mathrm{~s}$, and $72^{\circ} \mathrm{C}$ for $1 \mathrm{~min}$, with a final extension at $72^{\circ} \mathrm{C}$ for $10 \mathrm{~min}$. The PCR products were separated on an $8 \%$ non-denaturing polyacrylamide gel and visualized after silver staining.

\section{Evaluation of the agronomic traits}

The reactions of adult plants to powdery mildew were tested using Blumeria graminis f. sp Tritici isolates E05 and E07. Wheat-rye derivative line 13-2-2, common wheat cv. W770B, rye, Kavkaz with $P m 8$, Amigo with Pm17, and the susceptible control Shaan229 were planted alternately. The reactions of adult plants to powdery mildew were evaluated in the field using a randomized complete block design with two replicates. The adult plants were inoculated using the artificial dusting method, and their reactions were scored at the heading stage using a scale from 0 to 9 , as described previously (Sheng and Duan, 1991). In the present study, a score of 0-1 was considered to be highly resistant (HR), 2 was moderately resistant (MR), 3 was moderately susceptible (MS), and $\geq 4$ was susceptible (S), whereas I indicated immunity.

The agronomic characteristics were evaluated by planting the lines in a randomized complete block design with two replicates in 2010, 2011, and 2012. Fifty whole plants were harvested from each block at the maturity stage. The yield-related traits, i.e., plant height, tillering, spike length, kernels per spike, spikelets per spike, and thousand-grain weight, were measured and compared between 13-2-2 and its parents, W770B and rye. Duncan's multiple range procedure $(\mathrm{P}<0.05$ and $\mathrm{P}<0.01)$ was used to test the differences in the means for each trait.

\section{RESULTS}

\section{Identification of rye chromatin in wheat-rye derivative line 13-2-2}

The results obtained with the five rye genome-specific SCAR markers, i.e., AF1/AF4, $D 15, F 3 / R 3, O 5$, and $P 13 L F / R$, showed that the expected bands were amplified in rye and 13-2-2, but were absent from the female parent W770B (Figure 1). This suggested that the derivative line 13-2-2 contained rye chromatin. 


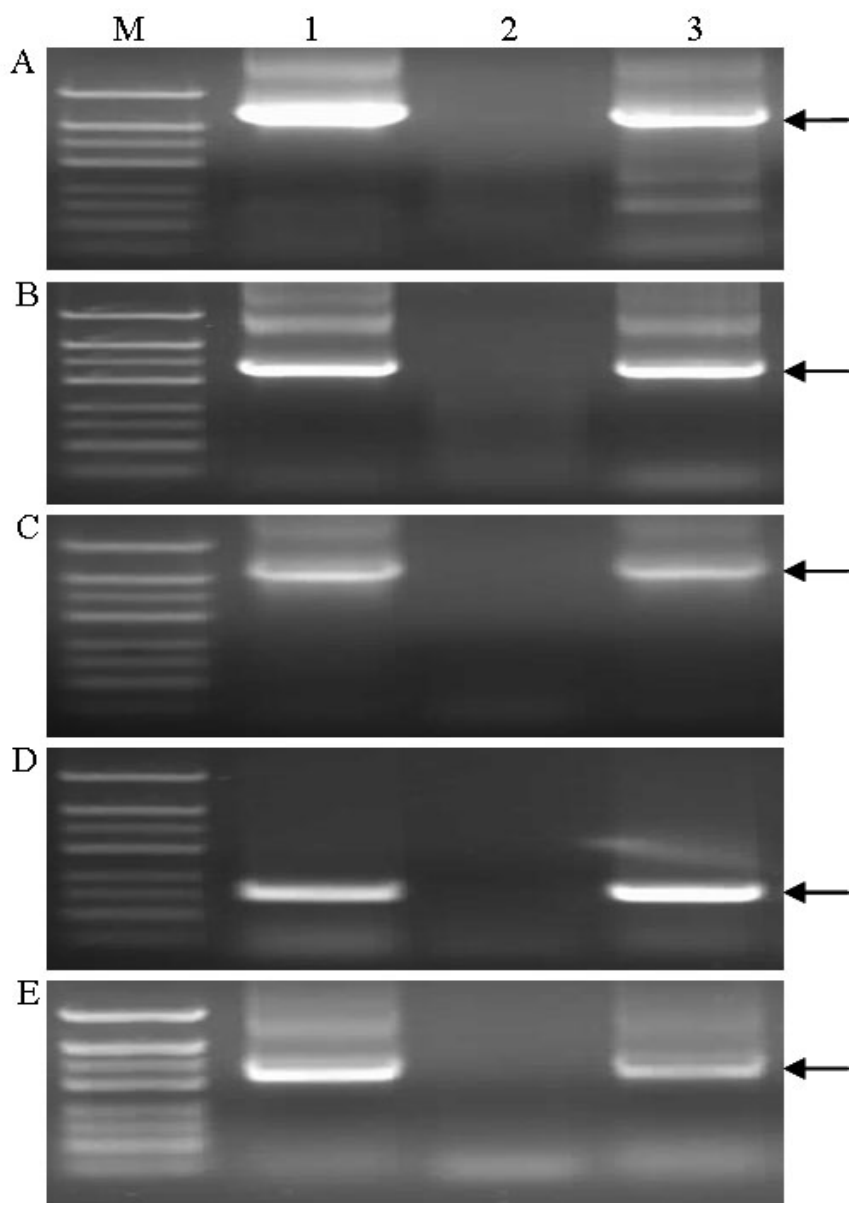

Figure 1. Analysis of rye genome-specific sequence-characterized amplified region (SCAR) markers: A. AF1/AF4, B. $D 15$, C. $F 3 / R 3$, D. O5FR, E. $P 13 L F / R$. Lane $M=$ marker; lane $1=$ rye; lane $2=\mathrm{W} 770 \mathrm{~B}$; lane $3=13-2-2$.

\section{Cytogenetic analysis of 13-2-2}

The mitotic and meiotic analyses showed that the chromosome number and configuration of $13-2-2$ were $2 \mathrm{n}=42=21$ II (Figure 2A and B). GISH analysis at the metaphase I stage of mitosis detected two strong yellowish-green hybridization signals related to the introgressed rye chromosome arms (Figure 2C). The result showed that 13-2-2 contained the two chromosome arms of rye and wheat chromosomes, and hence, it was designated a wheatrye translocation line. GISH analysis of pollen mother cells (PMCs) at meiotic metaphase I showed that 13-2-2 had two strong yellowish-green hybridization signals, which were positioned symmetrically in a rod bivalent (Figure 2D), thereby confirming that a pair of rye chromosome arms was introduced into 13-2-2. These results suggested that a wheat-rye translocation line 13-2-2 was developed, and that the alien rye chromosome arms can be transmitted stably in the wheat background. 

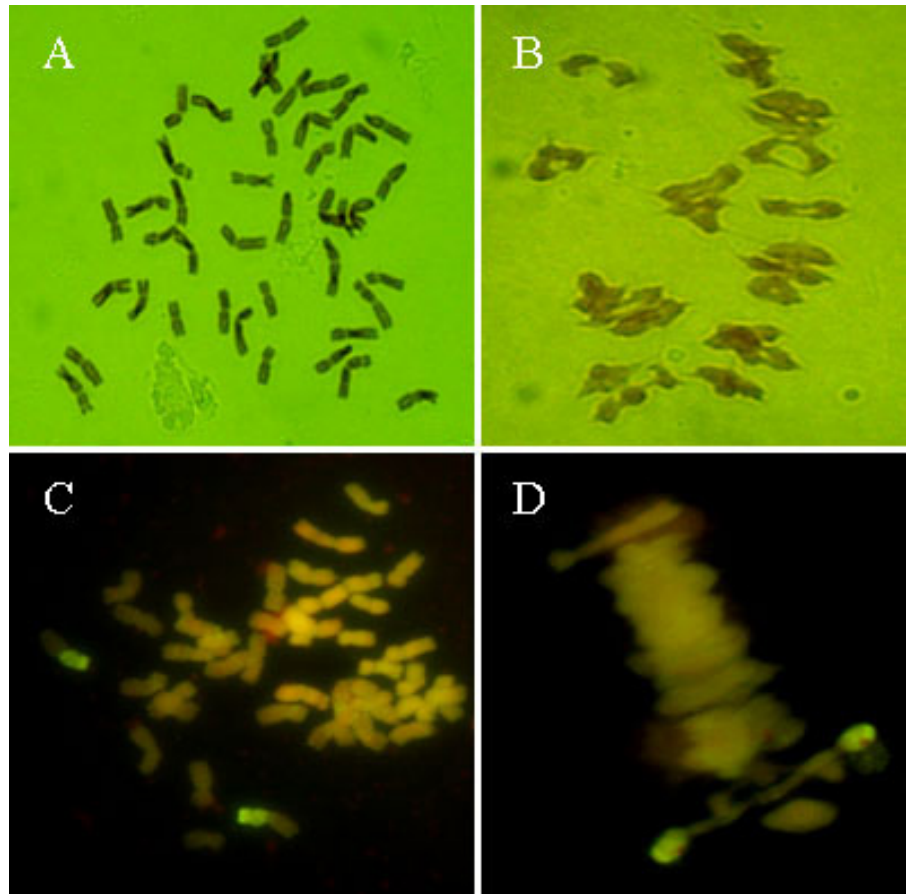

Figure 2. Cytology and genomic in situ hybridization (GISH) analysis of the mitotic and meiotic patterns of wheat-rye derivative line 13-2-2. A. Somatic chromosomes in the root tips, $2 n=42$. B. Chromosome behavior of pollen mother cells (PMCs) during metaphase I, $2 n=42$. C. Somatic metaphase I showing two rye chromosome arms. D. PMCs during meiotic metaphase I, indicating the two chromosome arms.

\section{Analysis using 1RS SCAR markers}

The analysis using 1RS-specific SCAR markers, i.e., IB-267, $\omega$-sec-p1/ $\omega$-sec-p2, and $\omega$-sec-p3/ $\omega$-sec-p4, showed that distinct bands were amplified in rye and 13-2-2, but were absent from the female parent W770B (Figure 3). Overall, the results of the rye genome-specific SCAR and GISH analyses confirmed that a pair of 1R short arms had been transferred into wheat.

\section{SSR analysis of 13-2-2}

In all, 320 SSR primer pairs on the long or short arms from seven wheat homoeologous groups were used to determine the chromosome arms of wheat that were substituted in the wheat-rye translocation line 13-2-2. The SSR analysis showed that only three primer pairs, i.e., Xgwm 163, Xwmc24, and Xgpw2277 (Table 1) distributed on 1AS, amplified none of the expected bands in 13-2-2, but were amplified in the common wheat W770B (Figure 4). The result suggested that 13-2-2 did not contain the 1AS chromosome but W770B did. The other markers amplified the expected bands in both 13-2-2 and W770B (data not shown). On the basis of the SSR results and previous assay results, we verified that the short $1 \mathrm{~A}$ arm of wheat had been substituted by the short $1 \mathrm{R}$ arm of rye. Finally, 13-2-2 was designated as a 1AL.1RS translocation line. 


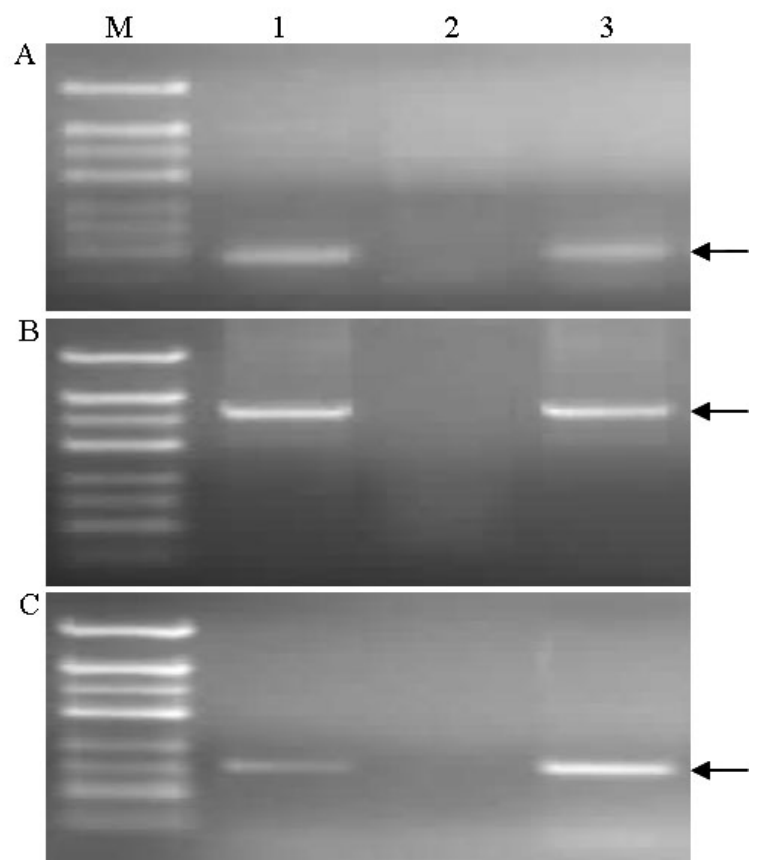

Figure 3. Analysis of rye 1RS chromosome-specific sequence-characterized amplified region (SCAR) markers. A. $I B-267$, B. $\omega$-sec-p1/p2, C. $\omega$-sec-p3/p4. Lane $M=$ marker; lane $1=$ rye; lane $2=\mathrm{W} 770 \mathrm{~B}$; lane $3=13-2-2$.

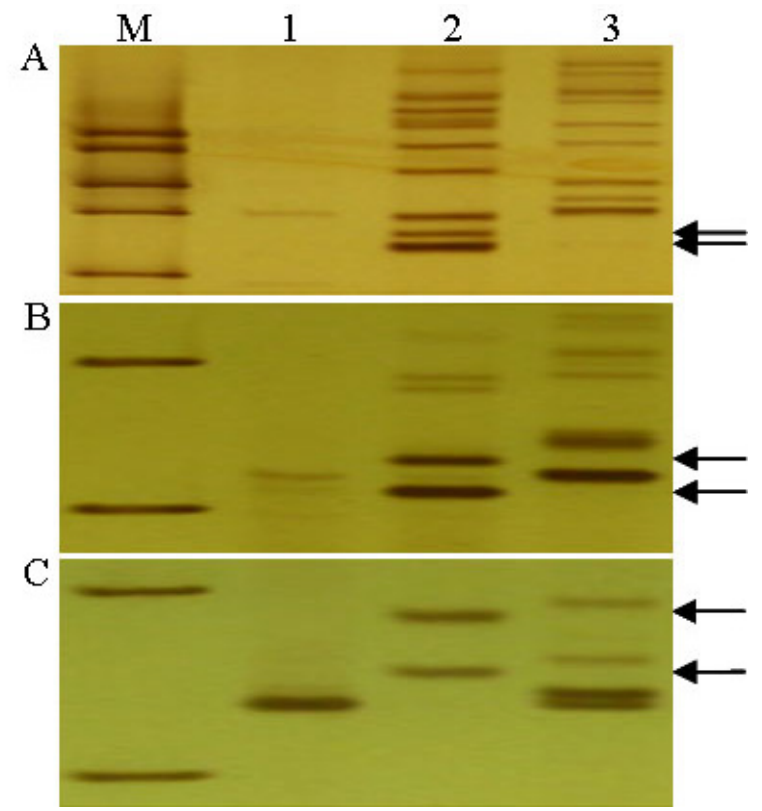

Figure 4. Analysis of the translocation line 13-2-2 and its parents, common wheat cv. W770B and rye, by using simple sequence repeat (SSR) markers: A. Xgwm163, B. Xwmc24, C. Xgpw2277. The arrows indicate the specific amplification products of $1 \mathrm{AS}$. Lane $M=$ marker; lane $1=$ rye; lane $2=\mathrm{W} 770 \mathrm{~B}$; lane 3=13-2-2. 


\section{Evaluation of the agronomic traits}

The inoculation trials were performed using Blumeria graminis f. sp. Tritici isolates E05 and E07. Line 13-2-2 and rye exhibited very high resistance, with an infection response score of I. In contrast, the maternal parent W770B, Kavkaz with Pm8, Amigo with Pm17, and the control cultivar Shaan229 were heavily infected with spores and had reaction response scores of S (Table 2). Therefore, we confirmed that the resistance gene(s) inherited from rye was present in 13-2-2 and was different from those present in Pm8 and Pm17.

\begin{tabular}{|c|c|c|c|c|c|c|}
\hline \multirow[t]{2}{*}{ Bgt isolate } & \multicolumn{6}{|c|}{ Materials } \\
\hline & $13-2-2$ & W770B & Rye & Kavkaz & Amigo & Shaan229 \\
\hline E05 & I & $\mathrm{S}$ & I & $\mathrm{S}$ & S & $\mathrm{S}$ \\
\hline E07 & I & $\mathrm{S}$ & I & S & S & S \\
\hline
\end{tabular}

Wheat cultivar "Shaan229" was used as a control for susceptibility. I = immune; S = susceptible.

Duncan's multiple range tests showed that plant height of 13-2-2 was greater than that of its parent common wheat W770B but less than of its male parent rye. The spike type of 132-2 was similar to that of common wheat W770B, i.e., a spindle type, and the spike length of 13-2-2 was similar to that of rye, whereas it was longer than that of W770B. In addition, the spikelet number per spike of 13-2-2 was similar to that of W770B, but lower than that of rye. The kernels of 13-2-2 were plump and larger than those of W770B and rye, whereas 13-2-2 had the highest average thousand-kernel weight (about $52 \mathrm{~g}$; Table 3).

Table 3. Evaluation of the agronomic traits of wheat-rye translocation line 13-2-2 and its parents W770B and rye.

\begin{tabular}{lccc}
\hline Characters & W770B & $13-2-2$ & Rye \\
\hline Plant height (cm) & $55(50-58)^{\mathrm{Bc}}$ & $75(70-78)^{\mathrm{Bb}}$ & $190(180-200)^{\mathrm{Aa}}$ \\
Tillering & $6(5-8)^{\mathrm{Aa}}$ & $8(7-10)^{\mathrm{Aa}}$ & $9(7-11)^{\mathrm{Aa}}$ \\
Spike length (cm) & $9(7-10)^{\mathrm{Ab}}$ & $13(11-14)^{\mathrm{Aa}}$ & $13(12-15)^{\mathrm{Aa}}$ \\
Kernels per spike & $52(44-62)^{\mathrm{Ab}}$ & $65(57-70)^{\mathrm{Aab}}$ & $75(60-80)^{\mathrm{Aa}}$ \\
Spikelets per spike & $17(15-18)^{\mathrm{Bb}}$ & $20(17-22)^{\mathrm{Bb}}$ & $35(30-40)^{\mathrm{Aa}}$ \\
Kernels per spikelet & $3(2-4)^{\mathrm{Aa}}$ & $3(2-4)^{\mathrm{Aa}}$ & $2(1-2)^{\mathrm{Aa}}$ \\
Average thousand-kernel weight $(\mathrm{g})$ & $45(42-48)^{\mathrm{Ab}}$ & $52(50-55)^{\mathrm{Aa}}$ & $22(18-25)^{\mathrm{Bc}}$ \\
\hline
\end{tabular}

Significant differences in the means are indicated at the $\mathrm{P}<0.01$ (capital letters) and $\mathrm{P}<0.05$ (lower-case letters) levels, according to Duncan's multiple range tests.

\section{DISCUSSION}

The wild relatives of wheat possess a large number of excellent genes that are valuable resources for the genetic improvement of wheat (Gill et al., 2006). Rye is a valuable source for alien chromosome translocations in wheat breeding, particularly the rye 1RS chromosome, which is one of the most widely used resources for wheat improvement (Weng et al., 2007; Yediay et al., 2010). The 1RS chromosome carries numerous excellent genes; hence, many wheat-rye 1RS translocation lines have been developed by breeders. However, the expression of exogenous hereditary material depends on the genetic background of common wheat to some extent. In the present study, we used common wheat W770B as the genetic background 
and developed a 1AL.1RS translocation line that showed resistance to powdery mildew. The chromosomal pairing behaviors of 13-2-2 were investigated in the PMCs during metaphase I, where 21 bivalents were observed in $93.8 \%$ of the PMCs. This suggests that the rye chromosomes have high heritability, and hence, the chromosome arms of rye could be maintained stably in the W770B background.

After chromosome-mediated gene transfer was performed, monitoring the presence of alien chromosomes or chromosome segments is important before they can be utilized in breeding programs (Zhang et al., 2007). Traditional cytogenetic techniques, enzyme-linked immunosorbent assay (ELISA), and protein electrophoresis have been used for the reliable screening of wheat lines containing alien chromatin, but these approaches are not suitable for breeding programs that require the rapid screening of large numbers of genotypes. Recent advances in molecular biology have allowed the extensive use of DNA molecular markers in genetic research and wheat breeding programs. DNA markers are rapid and reliable tools for detecting alien chromatin in wheat genetic backgrounds (Li et al., 2007). Rye is one of the most successful alien species; therefore, various DNA molecular markers have been developed specifically for its genome and chromosomes, which are used in wheat breeding programs. In the current study, we used five rye genome-specific SCAR markers, three 1RS chromosome SCAR markers, and three wheat 1AS chromosome SSR markers to trace the 1RS and $1 \mathrm{AS}$ chromosomes. These markers are suitable for the marker-assisted selection of wheatrye early crosses and can be used as tools for monitoring and tracking wheat-rye 1AL.1RS translocations during wheat breeding.

Most of the resistance genes ( $\operatorname{Lr} 26, \operatorname{Yr} 9, \operatorname{Pm} 8, \operatorname{Pm} 17$, and $\operatorname{Sr} 31)$ located on the 1RS chromosome are no longer effective against new disease biotypes because of their low genetic variability (Molnár-Láng et al., 2010). Several novel 1RS translocation lines or cultivars have been developed to maintain the yield traits and other excellent agronomic traits carried by the 1RS translocations, i.e., GRS1201 (Porter et al., 1994), 48112 and 89121 (Ji et al., 2008), R14 (Ren et al., 2009), and Mv9 kr1 (Molnár-Láng et al., 2010). These new translocation lines have recovered the resistance to diseases, but they have also expanded and enriched the available genetic variation. To exploit more genes from rye, we developed the novel 1AL.1RS translocation line 13-2-2 by crossing common wheat W770B with rye. The line had a high level of resistance to powdery mildew in the adult plant stages, whereas the maternal parent W770B Kavkaz with Pm8 and Amigo with Pm 17 were susceptible. Therefore, we suggest that the resistance gene(s) of 13-2-2 was inherited from rye and expressed in the common wheat (W770B) background. The resistance gene might be a novel resistance gene and different from Pm8 (Hanusova et al., 1996) and Pm 17 (Heun and Fribe, 1990) located on 1RS. In the future, we intend to locate and map the powdery mildew resistance gene(s) by developing interbred populations.

In conclusion, we developed a novel wheat-rye 1AL.1RS translocation line 13-2-2 that shows high resistance to powdery mildew; this line might become a useful genetic resource to facilitate powdery mildew resistance during wheat improvement. The molecular markers used in this study are rapid and reliable tools for wheat breeders, which could allow the detection and selection of wheat-rye 1AL.1RS translocation lines.

\section{ACKNOWLEDGMENTS}

Research supported by the Shaanxi Natural Science Foundation (\#2012JM3001) and the Tang Zhong-Ying Breeding Funding Project of the Northwest A\&F University. 


\section{REFERENCES}

Börner A and Korzun V (1998). A consensus linkage map of rye (Secale cereale L.) including 374 RFLPs, 24 isozymes and 15 gene loci. Theor. Appl. Genet. 97: 1279-1288.

Cota-Sánchez JH, Remarchuk K and Ubayasena K (2006). Ready-to-use DNA extracted with a CTAB method adapted for herbarium specimens and mucilaginous plant tissue. Plant Mol. Biol. Rep. 24: 161-167.

Francis HA, Leitch AR and Koebner RM (1995). Conversion of a RAPD-generated PCR product, containing a novel dispersed repetitive element, into a fast and robust assay for the presence of rye chromatin in wheat. Theor. Appl. Genet. 90: 636-642.

Friebe B, Jiang J, Raupp WJ and McIntosh RA (1996). Characterization of wheat-alien translocations conferring resistance to diseases and pests: current status. Euphytica 91: 59-87.

Gill BS, Friebe B, Raupp WJ and Wilson DL (2006). Wheat Genetics Resource Center: the first 25 years. Adv. Agron. 85: 73-135.

Hackauf B and Wehling P (2003). Development of microsatellite markers in rye: map construction. Plant Breed. Seed Sci. 48: 143-151.

Hanusova R, Hasm SLK, Babus P and Friedrich JZ (1996). Suppression of powdery mildew resistance gene Pm8 in Triticum aestivum L. (common wheat) cultivars carrying wheat-rye translocation TIBL.1RS. Heredity 77: 383-387.

Hess J, Kadereit JW and Vargas P (2000). The colonization history of Olea europaea L. in Macaronesia based on internal transcribed spacer 1 (ITS-1) sequences, randomly amplified polymorphic DNAs (RAPD), and intersimple sequence repeats (ISSR). Mol. Ecol. 9: 857-868.

Heun M and Fribe B (1990). Introgression of powdery mildew resistance from rye into wheat. Phytopathology 80: 242-245.

Ji J, Wang ZG, Sun JZ and Li JM (2008). Identification of new T1BL.1RS translocation lines derived from wheat (Triticum aestivum L. cultivar "Xiaoyan No. 6") and rye hybridization. Acta Physiol. Plant 30: 689-695.

Jia JQ and Yang ZJ (2010). Identification and Molecular Mapping of Yellow Rust New Resistance Genes in Wheat-Secale Africanum Introgression Lines. University of Electronic Science and Technology of China, 20-23.

Katto CM, Endo TR and Nasuda S (2004). A PCR-based marker for targeting small rye segments in wheat background. Genes Genet. Syst. 79: 245-250.

Ko JM, Do GS, Suh DY, Seo BB, et al. (2002). Identification and chromosomal organization of two rye genome-specific RAPD products useful as introgression markers in wheat. Genome 45: 157-164.

La Rota M, Kantety RV, Yu JK and Sorrells ME (2005). Nonrandom distribution and frequencies of genomic and ESTderived microsatellite markers in rice, wheat, and barley. BMC Genomics 6: 23-24.

Li XM, Lee BS, Mammadov AC, Koo BC, et al. (2007). CAPS markers specific to Eb, Ee, and R genomes in the tribe Triticeae. Genome 50: 400-411.

Liu C, Yang ZJ, Feng J and Chi SH (2007). Detection, mapping and application of a new repetitive DNA sequence in rye (Secale cereale L.) genome. Sci. Agric. Sin. 40: 1587-1593.

Lukaszewski AJ (2000). Manipulation of the 1RS.1BL translocation in wheat by induced homoeologous recombination. Crop Sci. 40: 216-225.

Mohler V, Hsam SLK, Zeller FJ and Wenzel G (2001). An STS marker distinguishing the rye-derived powdery mildew resistance alleles at the Pm8/Pm17 locus of common wheat. Plant Breed. 120: 448-450.

Molnár-Láng M, Cseh A, Szakács E and Molnár I (2010). Development of a wheat genotype combining the recessive crossability alleles kr1 kr1 kr2kr2 and the 1BL.1RS translocation, for the rapid enrichment of 1RS with new allelic variation. Theor. Appl. Genet. 120: 1535-1545.

Nagy ED and Lelley T (2003). Genetic and physical mapping of sequence-specific amplified polymorphic (SSAP) markers on the 1RS chromosome arm of rye in a wheat background. Theor. Appl. Genet. 107: 1271-1277.

Porter DR, Webster JA, Burton RL and Puterka GJ (1991). New sources of resistance to greenbug in wheat. Crop Sci. 31: 1502-1504.

Porter DR, Webster JA and Friebe B (1994). Inheritance of greenbug biotype G resistance in wheat. Crop Sci. 34: 625-628.

Puente R, González AI, Ruiz ML and Polanco C (2008). Somaclonal variation in rye (Secale cereale L.) analyzed using polymorphic and sequenced AFLP markers. In Vitro Cell. Dev. Biol. Plant 44: 419-426.

Rabinovich SV (1998). Importance of wheat-rye translocations for breeding modern cultivars of Triticum aestivum L. Euphytica 100: 323-340.

Ren TH, Yang ZJ, Yan BJ and Zhang HQ (2009). Development and characterization of a new 1BL.1RS translocation line with resistance to stripe rust and powdery mildew of wheat. Euphytica 169: 207-213.

Röder MS, Korzun V, Wendehake K, Plaschke J, et al. (1998). A microsatellite map of wheat. Genetics 149: 2007-2023. Schlegel R and Korzun V (1997). About the origin of 1RS.1BL wheat-rye chromosome translocations from Germany. 
Plant Breed. 116: 537-540.

Sebesta EE and Wood EAJ (1978). Transfer of greenbug resistance from rye to wheat with X-rays. Agron. Abstr. Am. Soc. Agron. 61-62.

Sheng BQ and Duan XY (1991). Improvement of scale 0-9 method for scoring adult plant resistance for powdery mildew of wheat. Beijing Agric. Sci. 1:38-39.

Stracke S, Schilling AG, Förster J and Weiss C (2003). Development of PCR-based markers linked to dominant genes for male-fertility restoration in Pampa CMS of rye (Secale cereale L.). Theor. Appl. Genet. 106: 1184-1190.

Villareal RL, Bañuelos O, Mujeeb-Kazi A and Rajaram S (1998). Agronomic performance of chromosomes 1B and T1BL.1RS near-isolines in the spring bread wheat Seri M82. Euphytica 103: 195-202.

Weng Y, Azhaguvel P, Devkota RN and Rudd JC (2007). PCR-based markers for detection of different sources of 1AL.1RS and 1BL.1RS wheat-rye translocations in wheat background. Plant Breed. 126: 482-486.

Wu J, Yang X, Wang H, Li H, et al. (2006). The introgression of chromosome 6P specifying for increased numbers of florets and kernels from Agropyron cristatum into wheat. Theor. Appl. Genet. 114: 13-20.

Yediay FE, Baloch FS, Kilian B and Özkan H (2010). Testing of rye-specific markers located on 1RS chromosome and distribution of 1AL.RS and 1BL.RS translocations in Turkish wheat (Triticum aestivum L., T. durum Desf.) varieties and landraces. Genet. Resour. Crop Evol. 57: 119-129.

Yu L, He F, Chen GL and Cui F (2011). Identification of 1BL·1RS wheat-rye chromosome translocations via 1RS specific molecular markers and genomic in situ hybridization. Acta Agric. Sin. 37: 563-569.

Zeller FJ and Fuchs E (1983). Cytologie und Krankheitsresistenz einer 1A/1R-und mehrerer 1B/1R-Weizen-RoggenTranslokationssorten. Z Pflanzenzüchtg 90: 285-296.

Zhang P, Friebe B, Gill BS and Park R (2007). Cytogenetics in the age of molecular genetics. Aust. J. Agric. Res. 58: 498-506.

Zhang H, Guan H, Li J, Zhu J, et al. (2010). Genetic and comparative genomics mapping reveals that a powdery mildew resistance gene M13D232 originating from wild emmer co-segregates with an NBS-LRR analog in common wheat (Triticum aestivum L.). Theor. Appl. Genet. 121: 1613-1621. 